\title{
Postembryonic development of tapeworms - source of novel phylogenetic characters for analysis of cestode evolution: comparative TEM studies
}

\author{
Z. ŚWIDERSKI ${ }^{1,2}$ \\ ${ }^{1}$ W. Stefański Institute of Parasitology, Polish Academy of Sciences, 51/55 Twarda Street, 00-818 Warsaw, Poland; \\ ${ }^{2}$ Department of General Biology and Parasitology, Warsaw Medical University, Chałubińskiego 5, 02-004 Warsaw, \\ Poland; E-mail: z.swider@twarda.pan.pl
}

\begin{abstract}
Summary
Ultrastructural features of juvenile cestodes (metacestodes) can provide useful characters for phylogenetic and evolutionary analyses. Until now, however, they have been relatively little utilised (Beveridge 2001, Chervy 2002). The postembryonic development and structure of fully formed metacestodes were examined in two cyclophyllideans: Taenia parva Baer, 1926 (Taeniidae); and Sobolevitaenia verulamii (Mettrick, 1958) Korniushin, 1972 (Dilepididae). In T. parva, three developmental stages were recognized: (1) an early stage of exogenous budding at the surface of the central vesicle; (2) a stage of polycephalic cyst development accompanied by segmentation of the growing metacestode strobila and an obvious decrease in the size of the central vesicle; (3) a fully formed metacestode of the strobilocercus type with $14-24$ invaginated scoleces. The tegument, scolex, subtegumental musculature of the strobilar segments, protonephridial system, calcareous corpuscles and medullary parenchyma of larvae exhibit general similarity to the same structures in adults at both LM and TEM levels. The morphogenesis of the metacestode of $T$. parva is compared with that of polycephalic metacestodes of other Taenia spp. (T. krepkogorski, T. twitchelli and T. endothoracica) and with other asexually multiplying metacestodes (Mesocestoides vogae, hymenolepidids and dilepidids). In S. verulamii, the body of the cysticercoid with invaginated scolex armed with a double crown of rostellar hooks was completely surrounded by the cercomer, which appears to be separated from the cyst and scolex. The surface of the suckers is covered with a thick layer of glycocalyx. Five cell types were distinguished in the sections: (1) perikarya of metacestode tegument; (2) glycolgen-storing parenchymal cells; (3) glandular-type cells with large, electron-dense secretory-like granules; (4) flame cells; and (5) calcareous corpuscle-forming cells. The surface of the cercomer is covered by elongated microvilli, which evidently differ from characteristic microtriches covering all other parts of the metacestode surface. The ul-
\end{abstract}

trastructure of $S$. verulamii evidently differs from that of the other dilepidid cestode examined to date, Lateriporus geographicus, the cyst wall of which more resembles cysticercoids of Hymenolepididae than those of Dilepididae. Concluding remarks: Ultrastructural studies on metacestodes have considerable promise for providing important new characters for phylogenetic analysis. New TEM data on a great variety of cestode species are urgently needed. Until now, this field has not been exploited in a systematic fashion. Until more comprehensive studies become available, the current data are not yet amenable to analysis.

Key words: cyclophyllidean cestodes; postembryonic development; comparative ultrastructure of metacestodes; cestode phylogeny and evolution

\section{Introduction}

New ultrastructural data on the ontogenetic, namely the postembryonic development of tapeworms, and on the morphology of their cercoid-type metacestodes can provide useful characters for analysis of cestode phylogenesis, systematics and evolution. They have been relatively little utilized until now (Beveridge, 2001; Chervy, 2002). Earlier reviews by Voge (1967), Freeman (1973) Šlais (1973), Jarecka (1975), and Ubelaker (1985) provide an excellent background for comparisons of the postembryonic developmental stages of tapeworms, which represent important comparative data on their ontogenesis and new characters for phylogenetic analysis. According to Beveridge (2001), available studies on the histology and ultrastructure of metacestodes have been, however, largely restricted to the classical 'cysticerci' and 'cysticercoids', limiting the possibilities of making comparison across all taxa within the Cyclophyllidea, and especially the wider array of cestode orders. In other words, a far greater diversity of ultrastructural data on a variety of cercoids is needed before we 
can apply them successfully as useful characters for analysis of cestode phylogeny. The purpose of this study is to briefly describe, recapitulate and compare the functional ultrastructure of the metacestodes of two cyclophyllidean cestodes Taenia parva Baer, 1926 (Taeniidae); and Sobolevitaenia verulamii (Mettrick, 1958) Korniushin, 1972 (Dilepididae). The present comparative study is based on our two previous papers describing the postembryonic development and functional ultrastructure of two above-mentioned species. For detailed descripton of results obtained recently on the cercoids of T. parva, see Świderski et al. (2007), whereas for the light microscopical data and preliminary TEM results on $S$. verulamii metacestodes see respectively Vakarenko and Korniushin (2002) and Świderski et al. $(2002 \mathrm{a})$.

\section{Materials and Methods}

Postembryonic development and the ultrastructure of fully formed metacestodes have been examined in two cyclophyllideans: Taenia parva Baer, 1926 (Taeniidae); and Sobolevitaenia verulamii (Mettrick, 1958) Korniushin, 1972 (Dilepididae).

Metacestodes of T. parva, kindly provided by Dr Jordi Miquel, Barcelona University, were obtained from the abdominal cavity of naturally infected wood mice, Apodemus sylvaticus L., 1758 (Rodentia, Muridae), captured in Quiaios, Portugal. For a detailed description of methods, see Świderski et al. (2007).

Metacestodes of $S$. verulamii were kindly provided by Prof. Vadim V. Korniushin and Dr E. Vakarenko, Institute of Zoology, NANU, Kiev, Ukraine. The cysticercoids of this species in various stages of development, identified on the basis of their scolex armament, were obtained from the millipede Glomerulis connexa Koch, 1847, the intermediate host of this species (Vakarenko \& Korniushin, 2001). The millipedes were collected in a leafy forest near Kiev, Ukraine. For more details, see Świderski et al. (2002).

All samples from both species were fixed in $4 \%$ glutaraldehyde in sodium cacodylate buffer $(\mathrm{pH} 7.4)$, rinsed in the same buffer, postfixed for $2 \mathrm{~h}$ in $1 \%$ osmium tetroxide, and routinely processed for TEM examination. Ultrathin sections were obtained using a Reichert-Jung Ultracut E ultramicrotome, placed on copper grids and double-stained with uranyl acetate and lead citrate. Ultrathin sections were examined using a Jeol 1010 TEM.

\section{Results}

Structure of the polycephalic cyst of T. parva

In $T$. parva (Fig. 1A - C), three developmental stages were recognized: (1) an early stage of exogenous budding at the surface of the central vesicle; (2) a stage of polycephalic cyst development accompanied by segmentation of the growing metacestode strobila and an obvious decrease in the size of the central vesicle; (3) fully formed metacestode strobila with $14-24$ invaginated scoleces attached to the remnants of the central vesicle.

The fully formed polycephalic metacestodes of $T$. parva, when examined closely, can be classified as the strobelocercus type of taeniid metacestode. The number of segments varies between 109 and 120 per strobila. The tegument, scolex, subtegumental musculature of the strobilar segments, protonephridial system, calcareous corpuscles and medullary parenchyma of metacestodes, when examined at at both LM and TEM levels, show general similarity to the coressponding structures in adult tapeworms. For detailed description of these structures, and different types of larval tissues see Świderski, et al. (2007).

\section{Structure of the cysticercoids of S. verulamii}

The metacestode of $S$. verulamii represents precisely the "monocysticercoid-type" sensu Chervy (2002). Its cercomer or tail appendage forming an additional cyst-shaped envelope around the real cyst (Fig. 2). In the cysticercoid of $S$. verulamii, the evaginated scolex with four suckers and invaginated rostellum armed with a double crown of rostellar hooks was completely surrounded by the cyst wall and the cercomer. The cercomer or tail appendages, transformed in this species into a spherical additional cyst wall, is evidently separated by a primitive lacuna from the real cyst surrounding scolex. The surface of the suckers is covered with a thick layer of glycocalyx. Five cell types were distinguished in the sections: (1) tegumental perikarya; (2) glycogen-storing and lipid-storing parenchymal cells; (3) the glandular-like cells with large, electron-dense granules; playing possibly a role of regulatory peptides in neuromuscular interactions, (4) flame cells; and (5) calcareous corpuscle-forming cells. The surface of the cercomer is elaborated into elongated microvilli, which evidently differ from characteristic microtriches covering all other parts of the metacestode surface. The body of the cysticercoid with evaginated scolex and invaginated rostellum with a double crown of rostellar hooks was completely surrounded by the modified spherical cercomer, which appears evidently separated by the primary lacuna from the cystwall protecting the scolex.

\section{Comparison of metacestode types}

The metacestode of T. parva is an example of a polycephalic cyst classified as "strobilocercus" which is characterristic for some taeniids. In the developed encysted metacestode of this species (Fig. 1C), $14-24$ strobila, arising from the central vesicle, were recorded. Each invaginated scolex of T. parva had four suckers and a rostellum with two alternating crowns of large and small rostellar hooks. In fully formed strobila, the number of segments ranged from 109 to 120. Each developed metacestode strobila, except for the invaginated scolex, resembled a miniature adult cestode. Within the metacestode segments, however, no primordia of genital organs were observed. Thus, these segments are not true proglottids.

The fully formed metacestode of $S$. verulamii (Fig. 2) is a characteristic cysticercoid and more precisely the "monocysticercoid-type" sensu Chervy (2002). The metacestode 


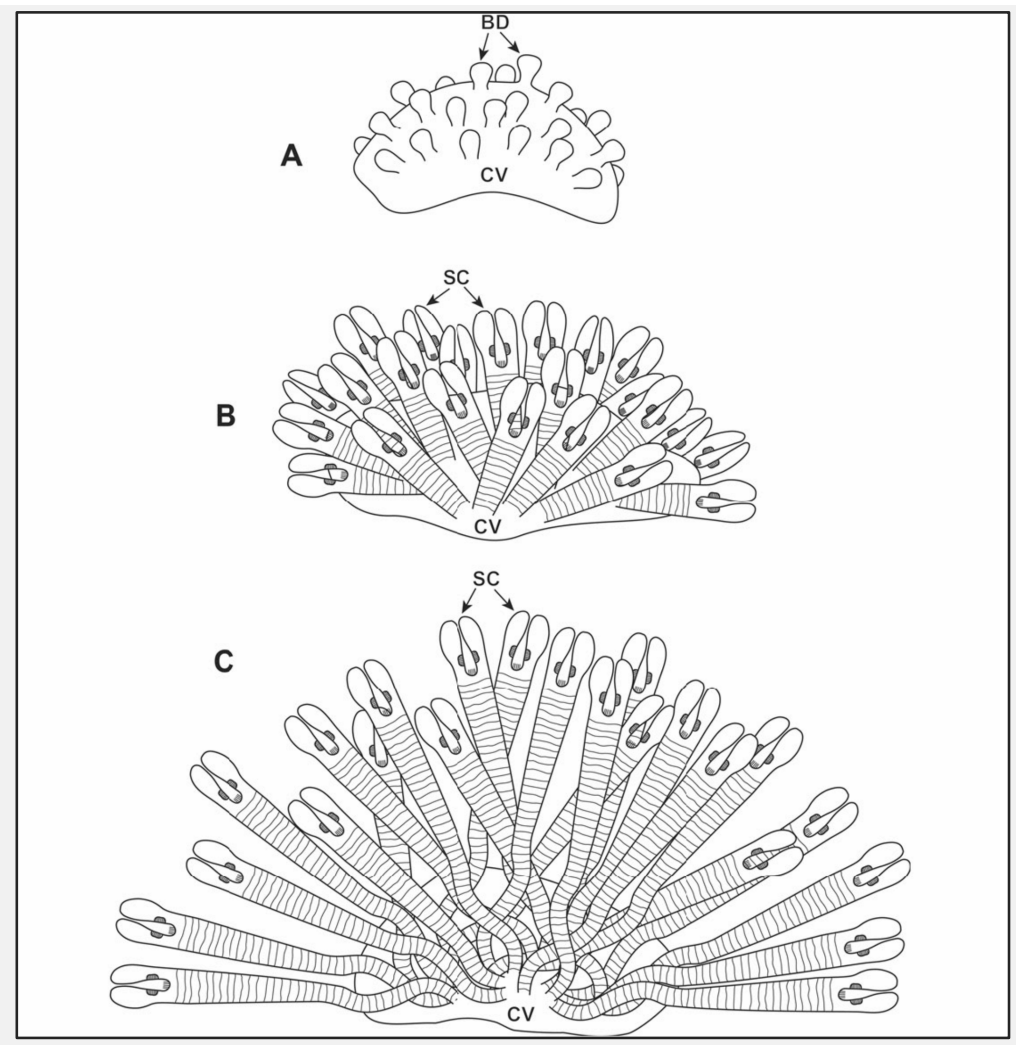

Fig. 1 A, B, C. Three consecutive stages of development of a polycephalic cyst of T. parva: A - Early stage of exogenous budding at the surface of the central vesicle; B - Stage of polycephalic cyst maturation, accompanied by (1) invagination of scoleces, 2) segmentation of growing

strobilocerci, and (3) decrease in size of the central vesicle; C - Fully formed, mature strobilocerci with invaginated scoleces. Note presence of much elongated strobila with obvious segmentation; and residual central vesicle, serving as an attachment point for the posterior ends of all strobilocerci which always remain united together. Abbreviations: $\mathrm{BD}$ - budds or primordia of scolices; CV - central vesicle; SC - scoleces (from Świderski et al., 2007, reproduced with permission of Acta Parasitologica)

of this species is an encysted cysticercoid surrounded by an additional spherical envelope originating from the modified cercomer or tail appendage. This cercomer is easily recognizable in the light microscope, after liberating the inside part of the true cysticercoid from the surrounding outer capsule formed by the cercomer tissue. It is also easily recognizable at the TEM level by its fine structure, namely microvillar tegument. The characteristic microvilli were observed only on the cercomer, whereas the tegument of other parts of the metacestode body has microtriches on the surface. Accordnig to Krasnoshchekov et al.(1985), the ultrastructure of $S$. verulamii evidently differs from that of the other dilepidid examined to date, Lateriporus geographicus, the wall of which more resembles cysticercoids of Hymenolepididae than those of Dilepididae (Świderski, et al., 2007).

The common ultrastructural features in the metacestodes of both cestode species in general resemble those of different types of organs and tissues in the corresponding structures of adult tapeworms. Also in both species, the characteristic microvilli were observed only on the cercomer, whereas the tegument of other parts of the larval body has microtriches at its surface.

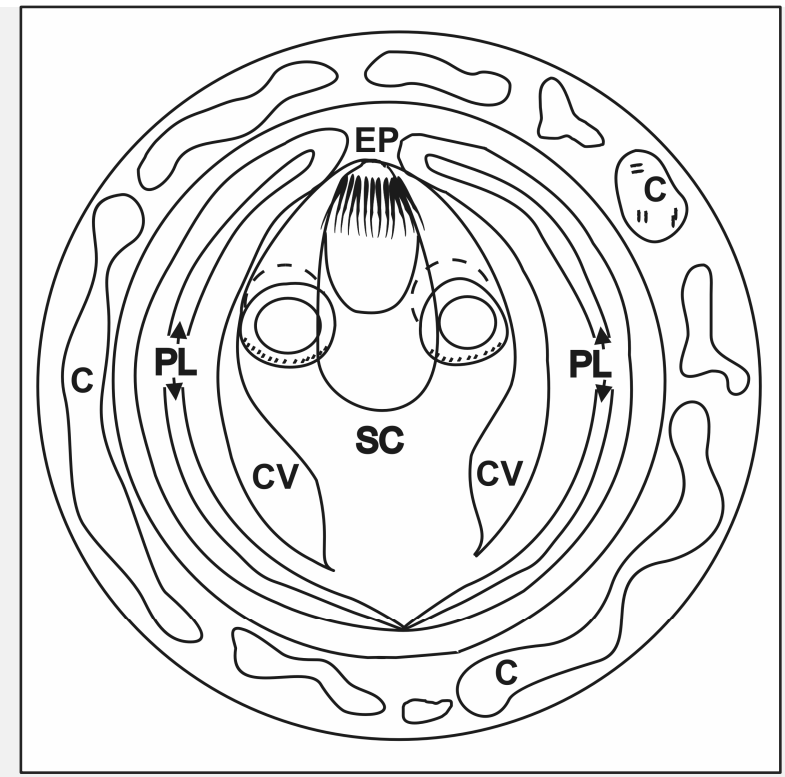

Fig. 2. Schematic representation of the cysticercoid of $S$. verulamii. Abbreviations: $\mathrm{C}$ - cercomer; $\mathrm{CV}$ - cyst cavity; $\mathrm{EP}$ - evagination pore; $\mathrm{PL}$ - primary lacuna; $\mathrm{SC}$ - scolex with invaginated rostellum and four suckers 


\section{Discussion}

\section{Developmental pattern}

The oncosphere larva carries in its body the germinative cells, which represent the primordia of the second postembryonic stage, the metacestode (Świderski, 1972, 1981, 1983; Świderski et al. 2000, 2002b; Swiderski \& Tkach, 1997, 1999; Świderski \& Mackiewicz, 2004; Młocicki et al., 2006). Most of the larval structures of the oncospheres are lost during development, and structures such as the somatic musculature, the hook musculature, the penetration glands and the oncospheral nerve cells do not persist in the metacestode. Our studies on the development of the T. parva and S. virulamii confirmed that all the metacestode structures are formed de novo and none of them, except the rudimentary oncospheral hooks on the cercomer, persist beyond the oncosphere stage. Therefore, the formation of the metacestode is a true metamorphosis (for detailed discussion see Stunkard, 1962; Conn, 2000, 2004, 2005).

\section{Comparative ultrastructure of metacestode tissues}

As mentioned in the results, certain metacestode structures and tissues, such as the tegument, scolex, subtegumental musculature of the strobilar segments, protonephridial system, calcareous corpuscles and medullary parenchyma, exhibit general similarity with the same structures in adults at both LM and TEM levels (Świderski, 1997; Świderski et al., 1970, 1973, 2002c; Młocicki et al., 2004, Świderski et al., 2007).

\section{Parenchyma}

Not only the nature of cestode parenchyma, but even its real existence as a discrete tissue remains so far unresolved. For instance, an important question for a long time has been whether the "parenchymal space" represents an inter- or intracellular compartment. It has been shown that much of the parenchymal tissue volume is made up of both voluminous lipid- and/or glycogen-rich cytoplasm and extracellular matrices (ECM) in cyclophyllideans (Conn \& Etges, 1984) and proteocephalideans (Conn \& Rocco, 1989), and that the dynamic interaction between parenchymal cells and ECM is involved in histogenesis in some cestodes (Conn, 1988b). Furthermore, the parenchyma of cestodes is similar in most respects to that of other classes within the phylum Platyhelminthes, which consists of both cellular and extracellular components (Conn, 1993).

\section{Asexual multiplication: comparison of different-types of} asexual larval reproduction

Asexual multiplication among metacestodes is not as common as it in the consecutive larval stages of trematodes. In cestodes it is restricted to cyclophyllideans (some members of the families Taeniidae, Hymenolepididae and Dilepididae), a few unidentified pseudophyllideans and to the some Mesocestodidae (for details, see Świderski et al. 2007). Of all the cestodes, metacestode asexual reproduce- tion is most common in the family Taeniidae, many species of which have the capacity for exogenous and/or endogenous budding. The greatly increased rate of asexual reproduction of Echinococcus hydatid cysts is potential unsurpassed by any other cestode. In the genus Taenia, asexually multiplying metacestodes of the cysticercus type occur in eight species (for details, see Swiderski et al., 2007). The morphogenesis of the metacestode of T. parva was recently compared with those of polycephalic metacestodes of other Taenia spp. (T. krepkogorski, T. twitchelli and T. endothoracica) and with other asexually multiplying metacestodes (mesocestoidids, hymenolepidids and dilepidids) (see Świderski et al., 2007). The unique feature of the asexual multiplication in some species of Mesocestodidae, which distinguish them from all other cestodes, is their capacity for asexual reproduction not only in the intermediate host but also in the gut of the definitive host (Smyth \& McManus, 1989). Galán-Puchades et al. (2002) described a new type of endogenous asexual prolixferation in metacestodes of Mesocestoides sp., adding to two other previously described types, longitudinal fission and exogenous budding. However, the fact that most $\mathrm{Me}$ socestoides spp. do not reproduce asexually remains an enigmatic feature of this genus (Conn 1986, 1988a, 1990, Conn et al., 2002).

\section{Comparative ultrastructure of dilepidid metacestodes}

The metacestode of $S$. verulamii represents cysticercoid classified more precisely as the so-called "monocysticercoid" type, sensu Chervy (2000). This type of metacestode was distinguished for the first time by Villot (1883) in Anomotaenia arionis (Siek, 1850) Fuhrman, 1908. Later, monocysticercoids were frequently described in Dilepididae "sensu stricto" among others by Gabrion (1974), Gabrion and Helluy (1982); Georgiev et al. (2005), Jarecka et al. (1984). Comparison of metacestode forms in dilepidids, allows us to distinguish four sub-types of cysticercoids: (1) monocercus, after Villot (1883) and Gabrion (1974); (2) cercoscolex, after Jarecka (1975); (3) plerocercoid, after Freeman (1973); and (4) strobilo-cysticercoid, after Freeman (1973). Only very few of the other above-mentioned sub-types of dilepidid cysticercoids were examined ultrastructurally. For example, the cysticercoid of the dilepidid, Lateriporus geographicus, as described by Krasnoshchekov et al. (1985) by means of TEM, evidently differs from the characteristic monocercoid of Dilepididae. Among other features, it differs in: (1) the absence of an exocyst of cercomer origin; (2) in structure of the superficial tegument syncytium and outer fibrous layer; (3) in presence of a layer of cytoplasmic processes bordering the cyst cavity. Krasnoshchekov et al. (1985) therefore concluded, that the ultrastructure of the cyst wall of L. geographicus metacestodes is more closely related to that of cysticercoids of Hymenolepididae than to monocysticercoids of Dilepididae. 


\section{Concluding remarks}

Both asexual multiplication and formation of polycephalic metacestodes, as observed in T. parva and other taeniids as well as in three other cestode families are considered here as the results of multiple and independent origins and should be regarded as a good example of convergent evolution. Asexual proliferation, highly developed in the metacestodes of some species, plays an important role in effecttive group infestation of the final hosts and undoubtedly increases the chances of completing the parasite life cycle. Until now, the ultrastructure of metacestode postembryonic developmental stages have been described only in a very few representatives of Dipepididae (Crowe et al., 1974; Gabrion, 1981; Jarecka et al., 1984; Krasnoshchekov et al., 1985). For a great majority of dilepidids the ultrastructural aspect of postembryonic development and metacestode structure have never been studied and still remain unknown.

Beveridge (2001) reviewed the application of life-cycle characters in cestode phylogeny, and stated emphasized that new LM and TEM data on a large numbe of varied species are needed to elucidate novel characters to better understand cestode evolution. In his opinion, histology and ultrastructure of metacestodes "offers considerable opportunities and appears to be a field which has, until now, not been exploited in a systematic fashion, but which offers considerable scope for future analysis". These studies, unfortunately, have not been pursued so much recently, although they can clearly provide direct evidence which might help to resolve many disputed questions concerning interrelationships between different cestode taxa and major evolutionary lineages. Ultrastructural and histological studies on metacestodes appear to have considerable promise of new characters for phylogenetic analysis, but as concluded by Beveridge (2001), until more comprehensive studies become available, the current data are not yet amenable to analysis.

\section{Acknowledgements}

The author wishes to acknowledge the contributions of the following to personal and/or internet discussions of some controversial questions concerning terminology and functional ultrastructure of metacestodes: I. Beveridge, D. B. Conn, C. Feliu, B. B. Georgiev, A. Jones, J. S. Mackiewicz., J. Miquel. All of them contributed to and/or kindly commented on an earlier version of the manuscript on $T$. parva larvae. Prof. D. B. Conn, in addition. kindly commented also on the present comparative studies, the final version of which was amended and re-edited by him. The author also extends his sincere thanks to Dr. J- Miquel and Dr. D. Młocicki for their assistance with two illustrations enclosed in this paper: Fig. 1 was made by Dr. J. Miquel and Fig. 2 was completed by Dr. D. Młocicki.

This article was not independently peer-reviewed and is published as submitted by the author.

\section{References}

BEVERIDGE, I. (2001): The use of life-cycle characters in studies of the evolution of cestodes. In LITTLEWOOD D. T. J., BRAY R. A. (Eds.): Interrelationships of the Platyhelminthes. Taylor \& Francis, London: $250-256$

CHERVY, L. (2002): The terminology of larval cestodes or metacestodes. System. Parasitol., 52: 1 - 33

ConN, D. B. (1986): Comparative fine structure of Mesocestoides spp. tetrathyridia. In M. J. HOWELL (Ed): Handbook of the $6^{\text {th }}$ Int Congress of Parasitol., Australian Academy of Science. Canberra: 114

CONN, D. B. (1988a): Fine structure of the tegument of Mesocestoides lineatus tetrathyridia (Cestoda: Cyclophyllidea). Int. J. Parasitol., 18: 133 - 135

CONN, D. B. (1988b): The role of cellular parenchyma and extracellular matrix in the histogenesis of the paruterine organ of Mesocestodes lineatus (Platyhelminthes: Cestoda). J. Morphol., 197: 303 - 314

ConN, D. B. (1990): The rarity of asexual reproduction among Mesocestoides tetrathyridia (Cestoda). J. Parasitol., 76: $453-455$

ConN, D. B. (1993): The biology of flatworms (Platyhelminthes): parenchyma cells and extracellular matrices. Trans. Amer. Microsc. Soc., 112: 241 - 261

ConN, D. B. (2000): Atlas of Invertebrate Reproduction and Development, $2^{\text {nd }} E d$. John Willey \& Sons Inc., New York

ConN, D. B. (2004): An overview of the biology of cestode larval/metacestode stages, and comparison with similar developmental stages in other animal taxa. Proc. $9^{\text {th }}$ Europ. Multicolloq. Parasitol., Valencia, Spain, 2004: 599

ConN, D. B. (2005): Comparative aspects of postembryonic development of cestodes (Platyhelminthes) and other animal taxa. In S. MAS-COMA (Ed.): Multidisciplinarity for Partasites, Vectors and Parasitic Disease. Proc. $9^{\text {th }}$ Europ. Multicolloq. Parasitol., Valencia. 2005: vol. 1: Articles of Keynote Speakers, Monduzzi Editore, Bologna: 319 - 325 CONN, D.B., ETGES, F.J. (1984): Fine structure and histochemistry of the parenchyma and uterine egg capsules of Oochoristica anolis (Cestoda: Linstowiidae). $Z$. Parasitkd., 70: 769-779.

Conn, D. B., Galán-Puchades, M. T., Fuentes M. (2002): Ultrastructure of cells and extracellular matrices in the hindbody of non-proliferative tetrathyridia of Mesocestoides lineatus. (Cestoda: Cyclophyllidea). In: Proc. $10^{\text {th }}$ Int. Congress of Parasitol., Vancouver, Monduzzi Editore, Bologna: 535 - 538

ConN, D. B., RocCO, L. J. (1989): Fine structure of the cellular parenchyma and extracellular matrix of Ophiotaenia loennbergii (Cestoda: Proteocephyllidea). Acta Zool. (Stockholm), 70: $105-110$

Crowe, D. G., Burt, M. D. B., ScotT, J. S. (1974): On the ultrastructure of polycerus larvae of Paricterotaenia paradoxa (Cesota: Cyclophyllidea). Can. J. Zool., 52: 1397 1411

FREEMAN, R. S. (1973): Ontogeny of cestodes and its bear- 
ing on their phylogeny and systematics. Adv. Parasitol., 11: $481-556$

GABRION, C. (1975): Étude expérimentale du développement larvaire d'Anomotaenia constricta (Molin, 1858) Cohn, 1900 chez un Coleoptere Pimelia sulcata Geoffr. Z. Parasitkd., 47: 249 - 262

GABRION, C. (1981): Ontogenèse de cestodes cyclophyllides. Étude morphogénétique du dévelopement pos-oncosphéral. Thèse présentée à l'Université des Sciences et Techniques du Languedoc, France. PhD Thesis, University of Science et Technics of Languedoc, France, (332 p.)

GABRION, C., HelluY, S. (1982): Développement lar-vaire de Paricterotaenia porosa (Cestoda: Cyclophyllidea) chez des Diptères du genre Chironomus, hôtes expérimentaux. Étude comparée des formes larvaires de Dilepididae.Ann. Parasitol. Hum. Comp., 57 : 33 - 525

Galán-Puchades, M. T., Fuentes, M., Conn, D. B. (2002): A new type of endogenous asexual proliferation in cyclophyllidean metacestodes. Acta Parasitol., 47: 288 293

Georgiev, B. B., SÁnchez, M. I., Green, A.J., Nikolov, P.N., VAsileva, G. P. Mavrodieva, R. S. (2005): Cestodes from from Artemia parthenogenetica (Crustacea, Branchiopoda) in the Odiel Marshes, Spain: a systematic survey of cysticercoids. Acta Parasitol., 50: $105-117$

JARECKA, L. (1975): Ontogeny and evolution of cestodes. Acta Parasitol. Polon., 23: 93 - 114

JARECKA L., BANCE, G.N., BURT M.D.B. (1984): On the life cycle of Anomotaenia micracantha dominicana Railliet et Henry, 1912), with ultrstructural evidence supportng the definition cercoscolex for dilepidid larvae (Cestoda, Dilepididae). Acta Parasitol. Polon., 29: 27 - 34

KrasnoshcheKov, G. P., Pluzhnikov, L. T., Gulyaev, V. D. (1985): Ultrastructure of the larval organ of metacestode Lateriporus geographicus Cooper, 1921 (Cestoda: Dilepididae). Folia parazitol. (Praha), 32: 51 - 59

MŁocicki, D., EIRA C., ŻEBrowsKA J., MiQuel J., ŚWIDERSKI, Z. (2004): Ultrastructure of the tegument of the anoplocephalid cestode Mosgovoyia ctenoides (Railliet, 1890) Beveridge, 1978. Wiad. Parazytol., 50: 579 - 585

MŁocicki, D., Świderski, Z., MiQuel, J., EirA, C., ConN, D.B. (2006): Cellular organisation of the oncosphere of Mosgovoyia ctenoides (Cestoda: Anoplocephalidae). J. Parasitol., 92: 953 - 961

STUNKARD, H.W. (1962): The organization, ontogeny and orientation of the Cestoda. Quart. Rev. Biol., 37: 23 - 34

ŠLAIS, J. (1973): Functional morphology of cestode larvae. Adv. Parasitol., 11: 395 - 480

SMYTH, J. D., Mcmanus, D. P. (1989): The Physiology and Biochemistry of Cestodes. Cambridge University Press, U.K.

ŚWIDERSKI, Z. (1972): La structure fine de l'oncosphere du cestode Catenotaenia pusilla (Goeze, 1782) (Cyclophyllidea, Catenotaeniidae). La Cellule, 69: 205 - 237

ŚWIDERSKI, Z. (1981): Reproductive and developmental biology of the cestodes. In W.H. CLARK, JR. AND T.S. ADAMS (Eds.): Advances in Invertebrate Reproduction. Elsevier/North Holland, New York, Amsterdam, Oxford
ŚWIDERSKI, Z. (1983): Echinococcus granulosus: hookmuscle system and cellular organisation of the infective oncospheres. Int. J. Parasitol., 13: 289 - 299

ŚWIDERSKI, Z. (1997): Ultrastructure of the oncospheral nerve cells in Echinococcus granulosus and E. multilocularis. In A. MENZAS DA SILVA (Ed.): Archivos Internationales de la Hidatidosis. XVIII Int. Congress of Hydatidology, Lisboa, Portugal, 32: 126 - 128

ŚWIDERSKI, Z., CHOMICZ, L., GRYTNER-ZIECINA, B., SEREDA, M. J. (2002c): Ultrastructural characteristic of the oncospheral germinative cells in Echinococcus multilocularis and E. granulosus. Proc. $10^{\text {th }}$ Internat. Congress of Parasitol. - ICOPA X: Symposia, Workshops and Contributed Papers, Vancouver, Canada, 2002: 551 - 554

ŚWIDERSKI, Z., EuZET, L., SCHONENBERGER, N. (1973): Ultrastructures du systeme nephridien des Cestodes Cyclophyllides Inermicapsifer madagascariensis, Catenotaenia pusilla et Hymenolepis microstoma. La Cellule, 71: 7 - 18 ŚWIDERSKI, Z., HuGGEL, H., SCHŐNENBERGER, N., (1970): Electron microscopy of calcareous corpuscle formation and their ultrastructure in the cestode Inermicapsifer madagascariensis. Proceedings of the $7^{\text {th }}$ International Congress of Electron Microscopy, (Ed. J. André) 6-12 September, 1970, Grenoble, France: 821 - 822

ŚWIDERSKI, Z., MACKIEWICZ, J. S. (2004): Ultrastructural studies on the cellular organisation of the coracidium of the cestode Bothriocephalus clavibothrium Ariola, 1899 (Pseudophyllidea, Bothriocephalidae). Acta Parasitol., 49: $116-139$

Świderski, Z., Miquel, J., MŁocicki, D., Georgiev, B. B., EIRA, C., GRYtNER-ZIÊCINA, B., FEliU, C. (2007): Postembryonic development and ultrastructural characteristics of the polycephalic larva of Taenia parva Baer, 1926 (Cyclophyllidea, Taeniidae). Acta Parasitol., 52: 31 - 50

ŚWIDERSKI, Z., SEREDA, M.J., VAKARENKO, E., KoRNIUSHIN, V.V., SAlAMATIN, R.V. (2002A): Fine structure of the cysticercoid of the cestode Sobolevitaenia verulamii (Cyclophyllidea, Dilepididae). Proc. $15^{\text {th }}$ Internat. Congress on Electron Microscopy, Durban, South Africa, 2002, 2: $489-490$

Świderski, Z., TKaCh, V.V., VAucher C., (2000): Fine structure of the infective eggs of dilepidid cestode Hepatocestus hepaticus (Baer, 1932), a parasite of shrews. Acta Parasitol., 45: $71-82$

ŚWIDERSKI, Z., TKACH, V. V. (1997): Ultrastructural studies on the cellular organisation of the oncospheres of the nematotaeniid cestode, Nematotaenia dispar (Goeze, 1782). Acta Parasitol., 42: 158 - 167

ŚWIDERSKI, Z., TKACH, V. V. (1999): Electron microscopical studies on the cellular organisation of the oncospheres of the hymenolepidid cestode Staphylocystoides stefanskii (Zarnowski, 1954). Acta Parasitol., 44: 31 - 38

ŚWIDERSKI, Z., TKACH, V. V. (2002b): Ultrastructure of embryonic development of Inermicapsifer madagascariensis (Cestoda, Anoplocephalidae) with emphasis on the cellular organisation of the infective eggs. Acta Parasitol., 47: $105-120$

UBELAKER, J. E. (1983): Metacestodes: morphology and 
development, In ARME, C., PAPPAS, P.W (Eds): Biology of the Eucestoda, Academic Press, London \& New York, 1983. vol. 1: $139-175$

VAKARENKO, E. G., KoRniUshin, V.V. (2002): Description of a cysticercoid of Sobolevitaenia verulamii (Cestoda, Cyclophyllidea) from its intermediate host Glomeris connexa (Diplopoda, Glomeridae). Vest. Zool., 36: 61 - 64 (in Russian)

VILlot, A. (1883): Mémoire sur les cysticerques des ténias. Ann.Sci. Nat., 15: $1-61$

Voge, M. (1967): The post-embryonic developmental stages of cestodes. Adv. Parasitol., 11: 707 - 730 